\title{
Erratum to: The conversion rate of tuberculosis screening tests during biological therapies in patients with rheumatoid arthritis
}

\author{
Giovanna Cuomo $^{1,2} \cdot$ Virginia D'Abrosca $^{1}$ - Daniela Iacono ${ }^{1}$ - Ilenia Pantano ${ }^{1}$
}

Published online: 28 March 2017

(C) International League of Associations for Rheumatology (ILAR) 2017

Erratum to: Clin Rheumatol (2017) 36:457-461

DOI 10.1007/s10067-016-3462-z

The author name Virginia D'Abrosca was incorrectly listed in the original publication. The author name has been corrected here. The remainder of the original article content remains unchanged.

The online version of the original article can be found at http://dx.doi. org/10.1007/s10067-016-3462-z

Giovanna Cuomo

giovanna.cuomo@unina2.it

1 Dipartimento Medico-Chirurgico di Internistica Clinica e

Sperimentale "F. Magrassi - A. Lanzara", Seconda Università degli,

Studi di Napoli, Naples, NA, Italy

2 Department of Internal and Experimental Rheumatology,

Rheumatology Unit, Via Pansini, 5, 80130 Naples, Italy 